\title{
Prescribing pattern and monitoring of children with neuro developmental disorders who were treated with risperidone at Lady Ridgeway Hospital, Colombo
}

\author{
ADMA Herath, KDDR Goonawardena, SW Kotalawala, KB Fathima Fazmin, S Seneviratne
}

\section{Background}

Behavioural disturbances are a common and challenging issue in the management of neurodevelopmental disorders in children. Treatment with pharmacological methods becomes necessary when these behaviours interfere with the general wellbeing and daily activities of these children, and with therapeutic programmess. There is a growing evidence base for the use of risperidone in this context. However the use of this medication is limited by its side-effect profile and the need for consistent and regular monitoring of these side-effects. Currently there is a paucity of data on the usage patterns of risperidone and its side-effect profile in children in Sri Lanka.

Aims

To analyse the prescribing patterns, indications and monitoring of risperidone in children with a primary diagnosis of a neurodevelopmental disorder who were prescribed risperidone.

\section{Methods}

This was a retrospective study carried out in University Psychological Medicine Unit, Lady Rideway Hospital for Children, Colombo (LRH). All children diagnosed with Neurodevelopmental disorders in the years 2013 and 2014 who were commenced on risperidone were included.

\section{Results}

A total of 27 children, 14 in 2013 and 13 in 2014 were prescribed risperidone. This amounted to $2.1 \%$ of the total number of referrals in 2013 and $2.6 \%$ in 2014. Majority were males (77.8\%) and ages ranged from 4 years and 3 months to 13 years. The main diagnosis was attention deficit hyperactivity disorder (29\%) and aggression was the commonest indication (40.74\%). Initial weight of the patient was not measured in $59.3 \%$ and weight gain thereafter was monitored only in two patients. Other common side effects were not monitored. Tardive dyskinesia was reported in one child. Pre-treatment investigations were not done in a majority (92.59\%). Post-treatment monitoring was not done in $44.4 \%$.

\section{Conclusion}

Prescription of risperidone for neurodevelopmental disorders was found to be used very sparingly in this sample. Deficiencies in monitoring for side effects were identified highlighting the need for regular monitoring.

Key words: risperidone, neurodevelopmental disorders, atypical antipsychotics, pre-treatment and post treatment monitoring

SL J Psychiatry 2016; 7(1): 15-17

\section{Introduction}

According to the 5th edition of Diagnostic and Statistical Manual (DSM 5) “Neurodevelopmental Disorders” include intellectual disability (intellectual developmental disorder), communication disorders, autism spectrum disorder, attention deficit hyperactivity disorder, specific learning disorder, and motor disorders (1). Behaviour problems commonly coexist in neuro developmental disorders. These behaviours can present as irritability, aggression, hyperactivity, insomnia or as self-injurious behaviours (2). These symptoms can manifest early in childhood and may last through adulthood causing serious problems in adaptation to their environments (3).
There are a number of different treatment modalities to manage these difficulties. Although behavioural interventions may reduce aggression and self-injury, it tends to be highly individualised and has not been evaluated in randomised clinical trials (4). These interventions also require specialised skills and effort that may not always be readily available. Pharmacological treatment can be considered in patients when behavioural problems interfere with general wellbeing, daily activities and with the therapeutic program (3). Only two medications, risperidone and aripriprazole have been approved by the Food and Drug Administration specifically for use among individuals with ASD who have serious behavioural problems (5). Risperidone is 
an antagonist of both dopamine (D2) and serotonin receptors (5-HT2A and others) and has proved to be relatively free of extrapyramidal side effects (EPSE) (6). This is particularly so when used at lower doses. Risperidone has been found to be safe and effective for the short-term treatment of tantrums, aggression, and self-injurious behaviour in children with autistic disorder. Improvements were also observed in stereotypic behaviour and hyperactivity (7).

One of the most problematic side effects of risperidone is weight gain. Other adverse effects are somnolence, sedation, stomach upset, EPSE, prolactin elevation, and weight gain. Monitoring for side effects and improvements in symptoms when prescribing risperidone is essential, just as it is with other medications (8).

Internationally guidelines have been developed by various clinical bodies to fulfil these requirements. However, strictly adhering to monitoring guidelines is not always feasible in a busy clinic setting, due to the lack of resources and time.

\section{Methodology}

A survey was carried out on all children attending the University Child Psychiatry Unit, LRH who were prescribed risperidone during the years 2013 and 2014. Data was extracted from patient records using a specifically designed data extraction form. The data included the initial diagnosis, age of child, indication for use, starting dose, recorded side effects and investigations performed were extracted.

\section{Results}

Twenty seven children were commenced on risperidone during this period. Only 2.1\% (14 from 667 registered patients) of total registered children in 2013 and 2.6\% (13 from 538 registered patients) in 2014 were prescribed risperidone. Majority were males $(77.8 \% ; n=21)$. The age range was from 4 years and 3 months to 13 years. (Mean age $=6$ years and 1 month). The distribution of patients' diagnoses is given in table 1 .

There were many reasons for the commencement of risperidone in this population. In some it was as the main mode of treatment (e.g; tic disorder) for the disorders itself while for many the reason was for management of behavioural concerns such as aggression. The indication for commencement of treatment is shown in table 2 .

The main pre-treatment screening measures include parameters such as height, weight, blood pressure and pulse rate. In our sample the initial weight was measured only in 11 (40.7\%).

Table 3 describes the distribution pattern of the duration of treatment with risperidone. While $37 \%$ had been on medication for less than 6 months, $14.8 \%$ were on risperidone treatment for over 18 months. Patients need to be monitored regularly for side effects both by clinical examination and blood investigations. Post treatment monitoring was done at 3 months on 7 (25.9\%) children and $8(29.6 \%)$ at 6 months. However, $44.4 \%$ had not had any post treatment evaluation.

\begin{tabular}{|c|c|c|}
\hline Diagnosis & $\begin{array}{l}\text { Number of } \\
\text { children }\end{array}$ & $\%$ \\
\hline ADHD & 8 & 29.63 \\
\hline Intellectual disability & 2 & 7.40 \\
\hline Autism & 7 & 25.92 \\
\hline Tic disorder & 3 & 11.11 \\
\hline Trichotillomania & 1 & 3.70 \\
\hline $\begin{array}{l}\text { Disruptive behaviour } \\
\text { disorder }\end{array}$ & 4 & 14.81 \\
\hline Depression & 2 & 7.40 \\
\hline Total & 27 & 100.00 \\
\hline
\end{tabular}

\begin{tabular}{|c|c|c|}
\hline Indication & $\begin{array}{l}\text { Number of } \\
\text { children }\end{array}$ & $\%$ \\
\hline Aggression & 11 & 40.74 \\
\hline Stereotypies & 1 & 3.70 \\
\hline Poor sleep & 1 & 3.70 \\
\hline Hyperactivity & 5 & 18.51 \\
\hline Temper tantrums & 6 & 22.22 \\
\hline Anxiety & 3 & 11.13 \\
\hline Total & 27 & 100.00 \\
\hline
\end{tabular}

Table 3. Distribution of the duration of treatment

\begin{tabular}{|lrr|}
$\begin{array}{l}\text { Duration of treatment } \\
\text { with risperidone } \\
\text { (months) }\end{array}$ & $\begin{array}{c}\text { Number of } \\
\text { children }\end{array}$ & $\%$ \\
\hline Less than 6 months & 10 & 37.00 \\
6-12 months & 9 & 33.30 \\
12-18 months & 4 & 14.80 \\
More than 18 months & 4 & 14.80 \\
Total & 27 & 100.00 \\
\hline
\end{tabular}




\section{Discussion}

Risperidone was used sparingly in this study population. Highest number of prescriptions was for children with attention deficit hyperactivity disorder (29.63\%) followed by autism spectrum disorder (25.92\%). The literature suggests a role for risperidone in the management of ADHD symptoms in the context of disruptive behaviour disorders (9). However, this remains an offlabel indication. It is only approved for the short term use for the management of behavioural issues in children with autism (10). In our study the indications for prescribing risperidone were more varied.

Behavioural issues are fairly common in children with developmental disorders and are very challenging to treat (9). A considerable number of individuals with neurodevelopmental disorders are being prescribed psychotropic medication, and once prescribed it is likely that they will remain on these medications for many years (11). Objective measurements of the target behaviour is vital in evaluating the response to treatment and to decide on treatment duration. In our current clinical setting there are no objective measures to guide the clinician on the time duration for cessation of treatment. This could have inadvertently led to long durations of treatment where $14.8 \%$ of the population were on risperidone treatment even after 24 months.

The recommended risperidone dose varies from $0.01 \mathrm{mg} /$ day to $0.05 \mathrm{mg} /$ day with a low starting dose and a gradual increase. No calculations had been made according to the weight of the children in our sample. However the doses used were relatively low, ranging from $0.25 \mathrm{mg}$ $1 \mathrm{mg}$ per day.

Risperidone is an antipsychotic with many side effects. This highlights the need for post treatment monitoring. Guidelines have been set to enable better monitoring of this population. The study points out the deficiencies in monitoring in this population with only $25.9 \%$ having been monitored at 3 months and only $29.6 \%$ at 6 months. Based on the findings of this study, we have developed guidelines for the use of oral risperidone in the management of severe behavioural disturbances in children with neurodevelopmental disorders.

\section{Limitations}

This study had certain limitations. It was conducted only in one clinical setting; hence the results are difficult to generalize. Another factor is the limited number of participants in the study. The entire data set was gathered from the patient records and some investigations done from laboratories other than the hospital laboratory might not have been included in the records.

\section{Declaration of interest}

None

\author{
ADMA Herath, KDDR Goonawardena, SW Kotalawala, \\ KB Fathima Fazmin, S Seneviratne, Lady Ridgeway \\ Hospital for Children, Colombo \\ Corresponding author: S Seneviratne \\ Email: sudasene@yahoo.co.uk
}

\section{References}

1. American Psychiatric Association (APA). Diagnostic and Statistical Manual of Mental Disorders. 5th ed. APA; Washington, DC; 2013.

2. Eapen V, Gururaj AK. Risperidone treatment in 12 children with developmental disorders and attention-deficit/ hyperactivity disorder. Prim Care Companion J Clin Psychiatry 2005; 7(5): 221-4.

3. Aman MG. Management of hyperactivity and other acting out problems in patients with autism spectrum disorder. Semin Pediatr Neurol 2004; 11: 225-8.

4. Schreibman L. Intensive behavioral/psychoeducational treatments for autism: research needs and future directions. J Autism Dev Disord 2000; 30: 373-8.

5. Scahill L, Koenig K, Carroll DH, Pachler M. Risperidone approved for the treatment of serious behavioural problems in children with autism. Psychopharmacology 2007; 20: 188-90.

6. Glick ID, Murray SR, Vasudevan P, Marder SR, Hu RJ. Treatment with atypical antipsychotics: new indications and new populations. J Psychiatr Res 2001; 35: 187-91.

7. McCracken JT, McGough J, Shah B, et al. Risperidone in children with autism and serious behavioral problems. $\mathrm{N}$ Engl J Med 2002; 347(5): 314-21.

8. Bishop JR, Pavuluri MN. Review of risperidone for the treatment of pediatric and adolescent bipolar disorder and schizophrenia. Neuropsychiatr Dis Treat 2008; 4(1): 55-68.

9. Pavuluri MN, Henry DB, Carbray JA, Sampson G, Naylor MW, Janicak PG. Open-label prospective trial of risperidone in combination with lithium or divalproex sodium in pediatric mania. Affect Disord 2004; 82 Suppl 1: S103-11.

10. Aman MG, Binder C, Turgay A. Risperidone effects in the presence/ absence of psychostimulant medicine in children with ADHD, other disruptive behaviour disorders, and subaverage IQ. J Child Adolesc Psychopharmacol 2004; 14(2): 243-54.

11. Esbensen AJ, Greenberg JS, Seltzer MM, Aman MG. A longitudinal investigation of psychotropic and nonpsychotropic medication use among adolescents and adults with autism spectrum disorders. J Autism Dev Disord 2009; 39(9): 1339-49.

12. Canitano R, Scandurra V. Risperidone in the treatment of behavioural disorders associated with autism in children and adolescents. Neuropsychiatr Dis Treat 2008; 4(4): 723-30. 